\title{
Reaction between Solid Iron and Liquid Zinc*
}

\author{
By Hideto Koga**, Yasuo Uchiyama** and Takafusa Aki**
}

\begin{abstract}
To study the interdiffusion between solid iron and liquid zinc, high purity iron test pieces were immersed into a high-purity zinc bath of 713-873 K. The thickness and the growth rate of alloy layers on the iron surface, and the quantity of iron reacted with zinc were measured.

A $\Gamma$ phase was formed next to the iron, followed by a $\delta_{1 \mathrm{~K}}$ phase. Up to $763 \mathrm{~K}$, a $\delta_{1 \mathrm{P}}$ phase and a $\zeta$ phase were formed next to the $\delta_{1 \mathrm{~K}}$ phase. The $\zeta$ phase thinned with immersion time, and disappeared at $763 \mathrm{~K}$. The growth rate of the $\delta_{1}$ phase was higher than that of the $\zeta$ phase. Over the temperature range between 773 and $833 \mathrm{~K}$, a $\left(\delta_{1}+\eta\right)$ mixture phase was formed next to the $\delta_{1}$ phase and dropped off into the bath. Above $833 \mathrm{~K}$, the $\delta_{1 \mathrm{~K}}$ phase formed on the surface of the alloy layers dropped off into the bath. Its thickness remained at about $10 \mu \mathrm{m}$. The total thickness of the alloy layers had a peak at about $793 \mathrm{~K}$.

Up to $1200 \mathrm{~s}$, the iron weight loss had a peak at $793 \mathrm{~K}$, but for 3000 and $6000 \mathrm{~s}$ immersions it had a peak at $773 \mathrm{~K}$. Above $813 \mathrm{~K}$, it was greater than those of other investigations. The quantity of iron remained in the alloy layers had a peak at about $793 \mathrm{~K}$, corresponding to the fact that the total thickness of the alloy layers had a peak at the same temperature; its peak value remained constant for a immersion time longer than $1200 \mathrm{~s}$. The quantity of iron dissolved into the zinc bath had a peak at $773 \mathrm{~K}$ for a immersion time longer than $3000 \mathrm{~s}$.
\end{abstract}

(Received October 25, 1978)

\section{Introduction}

The reaction between solid iron and liquid zinc is a basic process in hot dip galvanizing and has been studied by many investigators. Iron reacts with zinc and makes several intermetallic compounds shown in the $\mathrm{Fe}-\mathrm{Zn}$ phase diagram. These compounds are formed as layers and called the alloy layers. The alloy layers grow with immersion time.

It is known that when solid iron is immersed into liquid zinc at a given constant temperature, the variation in a iron weight loss with immersion time follows a parabolic law below $763 \mathrm{~K}$ and above $803 \mathrm{~K}$. Between 763 and 803 $K$, the iron weight loss varies with immersion time according to a linear law, and it shows a maximum at $773 \mathrm{~K}$. These temperature ranges are known, therefore, as a lower parabolic range, a linear range and an upper parabolic range ${ }^{(1)}$.

* This paper was originally published in Japanese in J. Japan Inst. Metals, 42 (1978), 136.

** Department of Materials Science and Engineering, Faculty of Engineering, Nagasaki University, 1-14 Bunkyo-machi, Nagasaki 852, Japan.

Trans. JIM
On the other hand, it was reported that the time when a linear relationship commenced was not identical with the time when iron was immersed, but with a certain delay ${ }^{(2)(3)}$. In the upper parabolic range, many different values of iron weight loss were reported ${ }^{(1)(4)(5)}$. Many different values of the time exponent for the growth of the alloy layers were also reported $^{(6) \sim(10)}$ as shown in Table 1. Thus there is still disagreement in the views of the reaction between solid iron and liquid zinc.

This paper describes the first stage of the study on the reaction between solid iron and liquid zinc; the reaction between pure iron and pure zinc in the temperature range of 713$873 \mathrm{~K}$ and for the time range of $60-6000 \mathrm{~s}$. This investigation was carried out by measuring three quantities of iron reacted with zinc;

Table 1 Exponent of time for the growth of the alloy layers.

\begin{tabular}{|c|c|c|c|}
\hline & $\Gamma$ & $\delta_{1}$ & $\zeta$ \\
\hline D. H. Rowland ${ }^{(6)}$ & 0.13 & 0.53 & 0.31 \\
\hline D. J. Blickwede ${ }^{(7)}$ & 0.099 & 0.60 & 0.156 \\
\hline F. Sjoukes ${ }^{(7)}$ & 0.23 & 0.58 & 0.26 \\
\hline D. Horstmann ${ }^{(7)}$ & 0.50 & 0.50 & - \\
\hline $\begin{array}{l}\text { M. Onishi et al. }{ }_{(\text {at } 685}^{(10)} \\
\text { K) }\end{array}$ & - & 0.55 & 0.42 \\
\hline
\end{tabular}

1979 Vol. 20 
the iron weight loss, the quantity of iron remained in the alloy layers, and the quantity of iron dissolved into the zinc bath.

\section{Experimental Procedure and Apparatus}

\section{Samples}

Electrolytic iron was remelted with a highfrequency vacuum induction furnace and cast into rods $30 \mathrm{~mm}$ in dia. Disks, $25.3 \mathrm{~mm}$ dia. $2 \mathrm{~mm}$ thick., were cut from these rods, and a small hole was drilled near the edge to suspend these disks for galvanizing. The chemical composition of electrolytic iron is shown in Table 2. The cut surface were abraded with successive grades of emery paper and finally polished with diamond paste. These disks were annealed at $1223 \mathrm{~K}$ for $1 \mathrm{~h}$ in vacuum, furnace cooled, repolished and degreased with trichloroethylene prior to tests.

Galvanizing baths were prepared with highpurity zinc $(99.99 \%)$, and a lead bath was prepared with pure lead of commercial grade.

\section{Galvanizing procedure}

A galvanizing furnace is shown in Fig. 1; an electric resistance furnace with two graphite crucibles, the lead bath and the zinc bath, in an atmosphere of argon. Two samples, one sample for measuring iron weight loss and the other for metallographic tests, were suspended with a silica rod, immersed first into the lead bath to pre-heat and immersed for $60-6000 \mathrm{~s}$ into the zinc bath maintained at 713-873 $\pm 1 \mathrm{~K}$. The galvanized samples were then quenched into water. The oxide film of the baths was skimmed just before immersing the samples. The zinc bath was freshly prepared for every immersion.

\section{Metallographic observation and thickness measurement}

One of the galvanized samples was cut

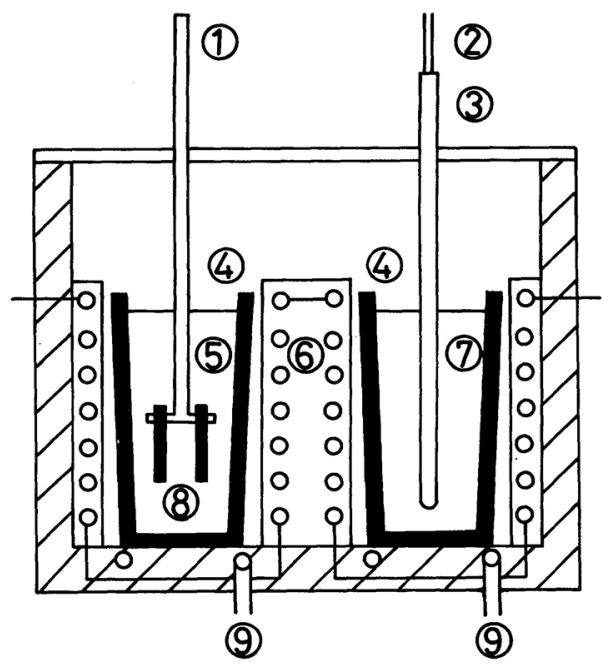

Fig. 1 Experimental apparatus. (1) suspension rod (silica), (2) CA thermocouple, (3) silica tube, (4) graphite crucible, (5) $\mathrm{Pb}$ bath, (6) heater, (7) $\mathrm{Zn}$ bath, (8) test pieces, (9) Ar gas inlet.

normal to the surface and mounted. The cut surface was polished, etched with $5 \%$ Nital, and observed with an optical microscope. The thickness of the alloy layers was measured with an ocular micrometer. Each thickness value represents the average of individual measurements from both surfaces. The iron-zinc compounds were identified by referring their microhardness values and structures to the previous investigations $^{(1) \sim(13)}$.

\section{Measurement of the quantity of iron reacted with zinc}

The other galvanized sample was stripped with inhibited hydrochloric acid solution. The iron weight loss was calculated from the difference in weight before and after stripping. The quantity of iron remained in the alloy layers was measured by colorimetric analysis of the solution used for stripping. The quantity of iron dissolved into the zinc bath was measured by the colorimetric analysis of the samples taken from the zinc bath after galvanizing. Colorimetric analyses were done by using an

Table 2 Chemical composition of electrolytic iron (wt $\%$ ).

\begin{tabular}{cccccccc}
\hline Element & $\mathrm{C}$ & $\mathrm{Si}$ & $\mathrm{Mn}$ & $\mathrm{P}$ & $\mathrm{S}$ & $\mathrm{Cu}$ & $\mathrm{Fe}$ \\
\hline $\mathrm{wt} \%$ & 0.005 & 0.005 & 0.005 & 0.004 & 0.005 & 0.004 & bal. \\
\hline \hline
\end{tabular}



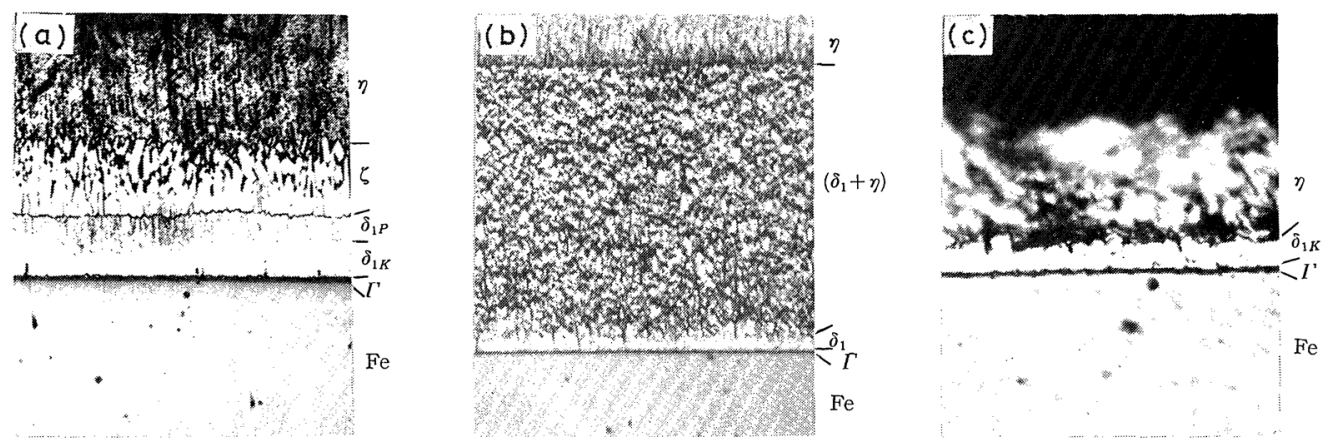

Photo. 1 Structures of the alloy layers at (a) $733 \mathrm{~K} \times 1200 \mathrm{~s}(\times 250 \times 2 / 3)$, (b) $793 \mathrm{~K} \times 1200 \mathrm{~s}$ $(\times 250 \times 2 / 3)$, and (c) $873 \mathrm{~K} \times 1200 \mathrm{~s}(\times 1000 \times 2 / 3)$.

autorecording spectrographic analyzer of the Hitachi 323 type.

\section{Experimental Results}

\section{Alloy layer structure}

Photograph 1 shows typical microstructures of the alloy layers formed in three temperature ranges mentioned above. At $713-753 \mathrm{~K}$, the alloy layers consisted of a $\Gamma$ layer next to the iron, followed by a $\delta_{1 \mathrm{~K}}$ layer $^{(12)}$, a $\delta_{1 \mathrm{P}}$ layer $^{(12)}$ and a $\zeta$ layer as shown in Photo. 1(a), and this alloy layer sequence was also made up at $763 \mathrm{~K}$ for a immersion time up to $1800 \mathrm{~s}$. The $\zeta$ phase was not formed as a layer at $763 \mathrm{~K}$ for 3000 and $6000 \mathrm{~s}$ immersions, but a $\left(\delta_{1}+\eta\right)$ mixture phase was formed. At $773-$ $803 \mathrm{~K}$, the alloy layers consisted of the $\Gamma$ layer next to the iron, followed by the $\delta_{1}$ layer $\dagger$ and the $\left(\delta_{1}+\eta\right)$ layer as shown in Photo. 1(b). The $\delta_{1}$ phase was divided into two phases, the $\delta_{1 \mathrm{~K}}$ and the $\delta_{1 \mathrm{p}}$, but it became difficult to distinguish the $\delta_{1 \mathrm{P}}$ from the $\delta_{1 \mathrm{~K}}$ as immersion temperature increased. The $\left(\delta_{1}+\eta\right)$ phase floated into a $\eta$ phase for a immersion time longer than $1800 \mathrm{~s}$ at these temperatures as shown in Photo. 2. At $813 \mathrm{~K}$, and at $833 \mathrm{~K}$ for a immersion time up to $600 \mathrm{~s}$, the $\left(\delta_{1}+\eta\right)$ phase was also formed, but the $\delta_{1 \mathrm{P}}$ phase was not formed. At $833 \mathrm{~K}$ for a immersion time longer than $600 \mathrm{~s}$, and at 853 and $873 \mathrm{~K}$, the alloy layers consisted of the $\Gamma$ layer and the $\delta_{1 \mathrm{~K}}$ layer as shown in Photo. 1(c). The $\delta_{1 \mathrm{~K}}$

$\dagger$ The $\delta_{1}$ means the $\left(\delta_{1 \mathrm{~K}}+\delta_{1 \mathrm{P}}\right)$ or the $\delta_{1 \mathrm{~K}}$.

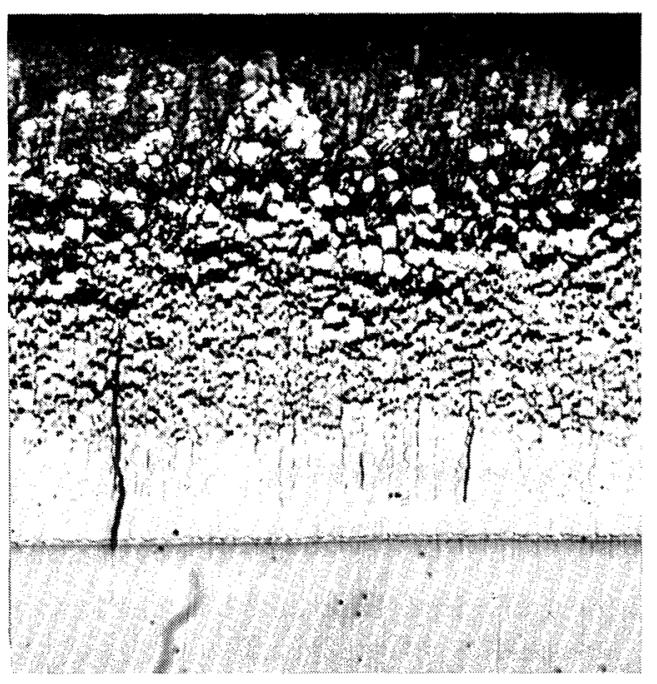

Photo. 2 Structure of the alloy layers at $773 \mathrm{~K} \times$ $6000 \mathrm{~s}(\times 250)$.

phase floated into the $\eta$ phase at these temperatures. The $\Gamma$ layer consisted of two layers, a $\Gamma$ and $\Gamma_{1}{ }^{(13)}$.

\section{Growth of the alloy layers}

Figure 2 shows the relation between the total alloy layers thickness and immersion temperature for various immersion times. For a constant immersion time, the total thickness of the alloy layers increased with rising immersion temperature, and had a peak in the region of $793 \mathrm{~K}$. At a constant immersion temperature up to $763 \mathrm{~K}$, it increased with immersion time. At $773-793 \mathrm{~K}$, it increased for a short immersion time, but for a immersion time longer than $1800 \mathrm{~s}$ it remained at about 


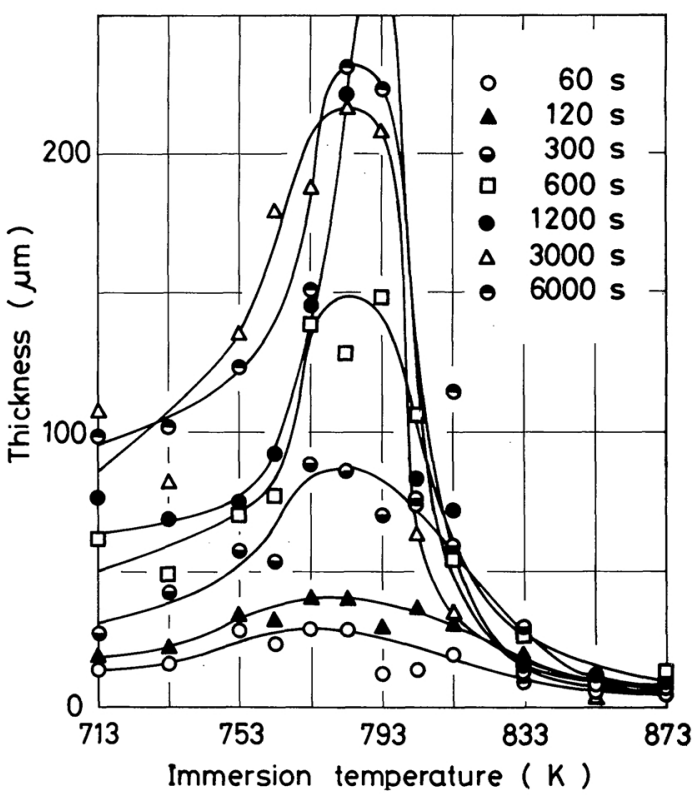

Fig. 2 Relation between the thickness of the alloy layers and immersion temperature for various immersion times.

$150 \mu \mathrm{m}$ at $773 \mathrm{~K}$, about $220 \mu \mathrm{m}$ at 783 and $793 \mathrm{~K}$. At 833 and $853 \mathrm{~K}$, it increased slowly and at $873 \mathrm{~K}$ it remained at about $10 \mu \mathrm{m}$. The time exponents for the growth of the alloy layers are shown in Table 3.

The $\zeta$ phase was columnar for a short immersion. For a long immersion, it was formed in a row of grains. Further immersion made the $\zeta / \delta_{1 \mathrm{p}}$ interface wavelike and thinned the thickness of the $\zeta$ layer as shown in Photo. 3.

Up to $813 \mathrm{~K}$, the thickness of the $\delta_{1 \mathrm{P}}$ layer increased with immersion time as shown in Table 3. Above $833 \mathrm{~K}$, its thickness was about $10 \mu \mathrm{m}$. The thickness of the $\left(\delta_{1}+\eta\right)$ layer increased with immersion time, but kept constant for a immersion time longer than $1800 \mathrm{~s}$ as the $\left(\delta_{1}+\eta\right)$ phase floated into the $\eta$ phase.

\section{Quantity of iron reacted with zinc}

Figures 3, 4 and 5 show the relation between the quantity of iron reacted with zinc and immersion temperature for various immersion times.

The iron weight loss increased with rising immersion temperature for a short immersion. But it had a peak at $793 \mathrm{~K}$ for $600-1200 \mathrm{~s}$ immersions and had a peak at $773 \mathrm{~K}$ for 3000

Table 3 Exponent of time for the quantity of iron reacted with zinc and the growth of the alloy layers.

\begin{tabular}{|c|c|c|c|c|c|}
\hline \multirow[b]{2}{*}{ Temp. (K) } & \multicolumn{3}{|c|}{ Iron reacted with zinc } & \multicolumn{2}{|c|}{ Thickness } \\
\hline & Total & in alloy & into zinc & Total & Delta 1 \\
\hline 713 & 0.58 & 0.69 & 0.55 & 0.48 & 0.65 \\
\hline 733 & 0.55 & 0.52 & 0.75 & 0.39 & 0.65 \\
\hline 753 & 0.57 & 0.48 & 0.71 & 0.35 & 0.57 \\
\hline 763 & 0.64 & $\begin{array}{c}0.63 \\
(60-1200)\end{array}$ & 0.89 & $\begin{array}{c}0.52 \\
(60-3000)\end{array}$ & $\begin{array}{c}0.74 \\
(60-3000)\end{array}$ \\
\hline 773 & 0.72 & $\begin{array}{c}0.74 \\
(60-1200)\end{array}$ & $\begin{array}{c}0.60 \\
(60-600)\end{array}$ & $\begin{array}{c}0.70 \\
(60-600)\end{array}$ & 0.39 \\
\hline 783 & $\begin{array}{c}0.80 \\
(60-1200)\end{array}$ & $\begin{array}{c}0.84 \\
(60-1200)\end{array}$ & 0.85 & $\begin{array}{c}0.71 \\
(60-1200)\end{array}$ & 0.68 \\
\hline 793 & $\begin{array}{c}0.92 \\
(60-1200)\end{array}$ & $\begin{array}{c}0.90 \\
(60-1200)\end{array}$ & 0.93 & $\begin{array}{c}1.05 \\
(60-1200)\end{array}$ & 0.72 \\
\hline 803 & 0.70 & $\begin{array}{c}1.06 \\
(60-600)\end{array}$ & 0.92 & - & $\begin{array}{c}0.75 \\
(60-1800)\end{array}$ \\
\hline 813 & 0.74 & $\begin{array}{c}0.63 \\
(60-600)\end{array}$ & 0.89 & 一 & $\begin{array}{c}0.60 \\
(60-1200)\end{array}$ \\
\hline 833 & 0.79 & - & 0.91 & - & - \\
\hline 853 & 0.95 & 一 & $\begin{array}{c}0.95 \\
(60-3000)\end{array}$ & - & 一 \\
\hline 873 & $\begin{array}{c}1.11 \\
(60-1800)\end{array}$ & 一 & $\begin{array}{c}1.06 \\
(60-1200)\end{array}$ & - & - \\
\hline
\end{tabular}

( ): Range of time (s) no parenthesize: $(60-6000)$ 

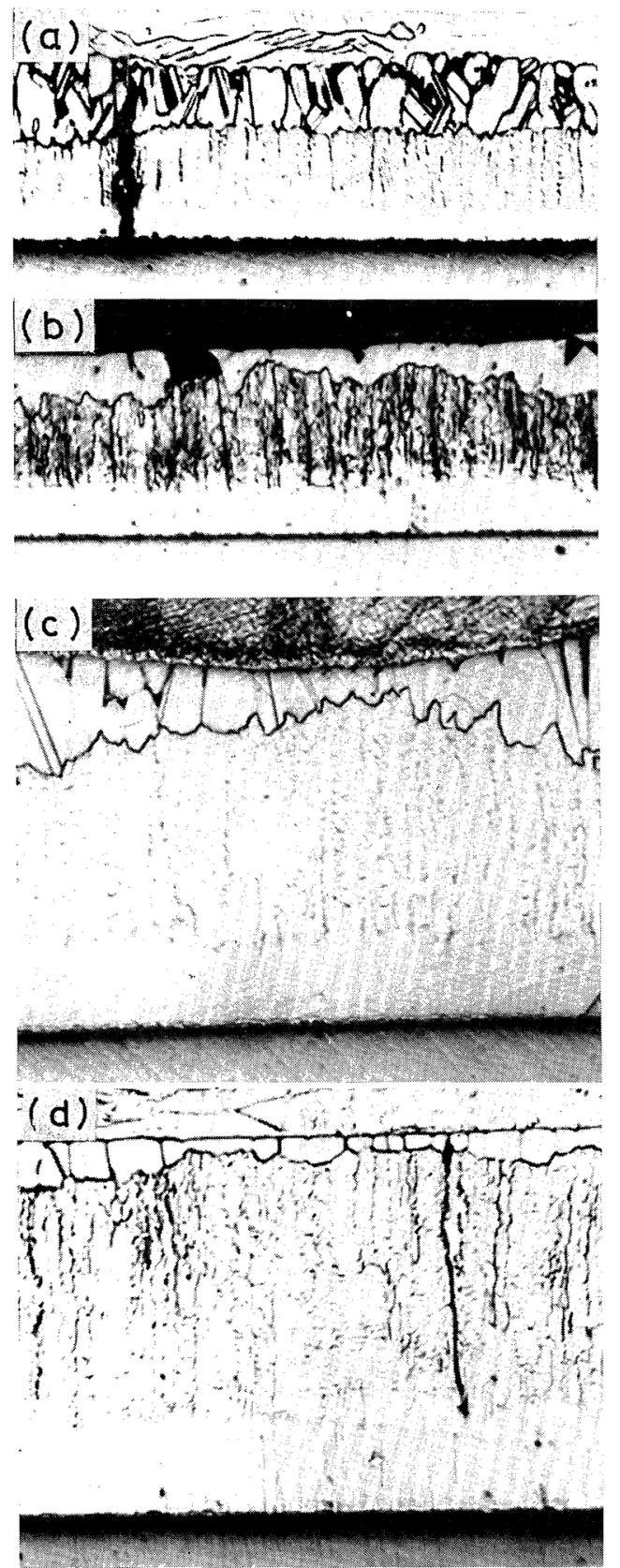

Photo. 3 Structures of the $\zeta$ phase at $753 \mathrm{~K}$ for (a) $600 \mathrm{~s}$, (b) $1200 \mathrm{~s}$, (c) $3000 \mathrm{~s}$, and (d) $6000 \mathrm{~s}(\times 250)$.

$6000 \mathrm{~s}$ immersions. Above the peak temperature, it decreased and then increased again with rising immersion temperature.

The quantity of iron remained in the alloy layers varied with immersion temperature,

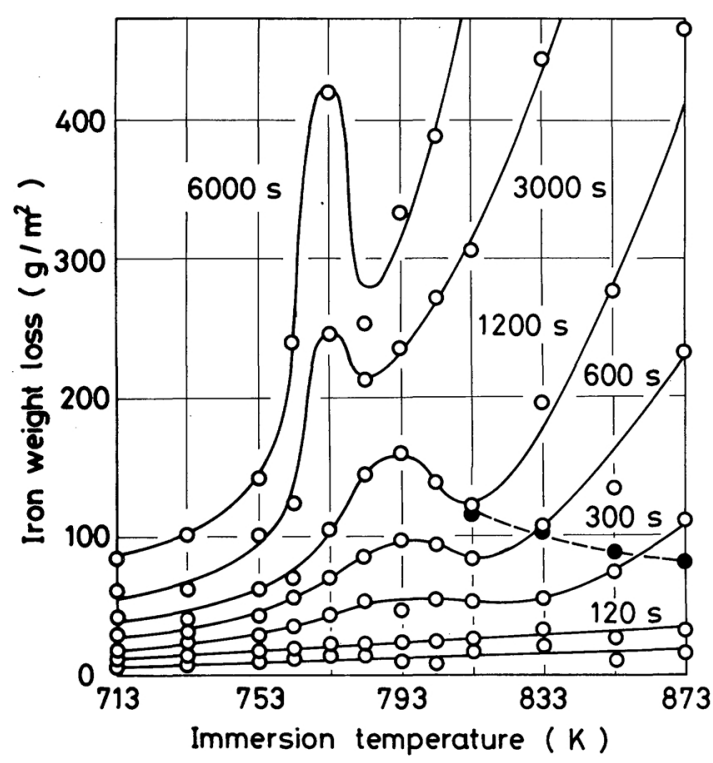

Fig. 3 Relation between the iron weight loss and immersion temperature for various immersion times ( iron-saturated zinc bath).

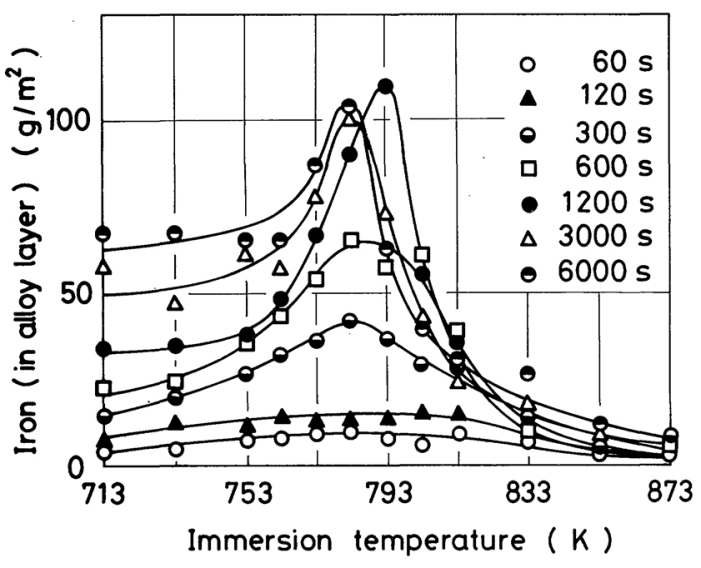

Fig. 4 Relation between the quantity of iron remained in the alloy layers and immersion temperature for various immersion times.

as with the total alloy layers thickness, and had a peak in the region of $793 \mathrm{~K}$, and above $833 \mathrm{~K}$ it did not exceed $6-7 \mathrm{~g} / \mathrm{m}^{2}$. A constant peak value of about $100 \mathrm{~g} / \mathrm{m}^{2}$ was obtained for a long immersion, corresponding to the fact that the total alloy layer thickness became constant for a long immersion.

The quantity of iron dissolved into the zinc bath increased with rising immersion temperature for a short immersion and had a peak at 


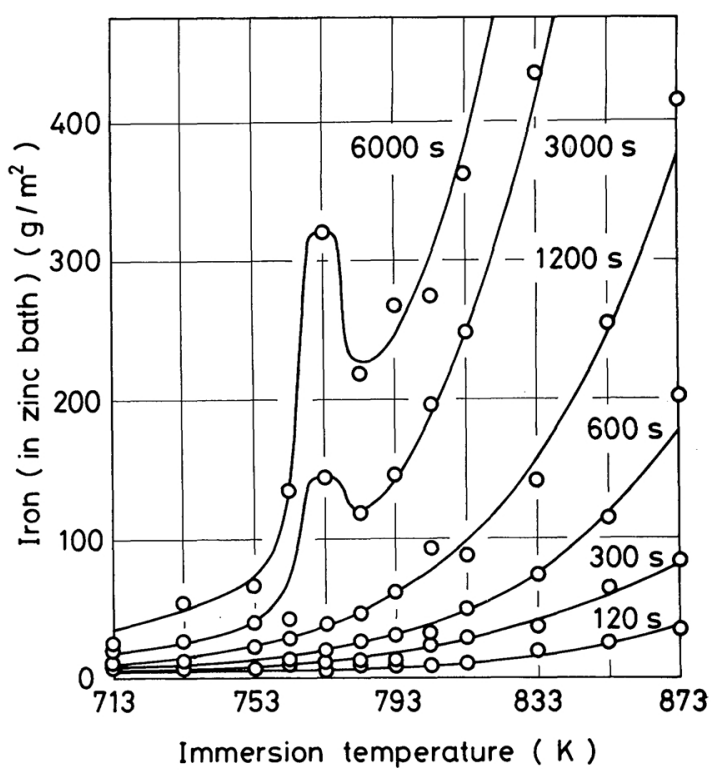

Fig. 5 Relation between the quantity of iron dissolved into the zinc bath and immersion temperature for various immersion times.

$773 \mathrm{~K}$ for $3000-6000 \mathrm{~s}$ immersions. An activation energy of $148 \mathrm{~kJ} / \mathrm{mol}$ was obtained from the temperature dependence of the quantity of iron dissolved into the zinc bath above $813 \mathrm{~K}$.

The time exponents for the quantity of iron reacted with zinc are shown in Table 3.

\section{Discussion}

\section{Structure and growth of the alloy layers}

Schramm ${ }^{(11)}$ reported that the $\zeta$ phase existed up to $803 \mathrm{~K}$, but Ghoniem ${ }^{(12)}$ reported that it existed below $768 \mathrm{~K}$. In a $\mathrm{Fe}(\mathrm{s})-\mathrm{Zn}(\mathrm{g})$ reaction, Short ${ }^{(14)}$ found it at $773 \mathrm{~K}$, and in the $\eta$ phase Allen ${ }^{(15)}$ reported that it was stable up to $803 \mathrm{~K}$. Thus the stable region of the $\zeta$ phase has not been decided as yet. In this work, it was found at $763 \mathrm{~K}$ and not at $773 \mathrm{~K}$.

The $\zeta$ phase thickness varied with immersion time in a suspecious manner below $753 \mathrm{~K}$, and decreased for a immersion time longer than $1800 \mathrm{~s}$ as shown in Photo. 3. Sjoukes ${ }^{(8)}$ reported that the $\zeta$ phase thickness increased in propotion to $t^{0.30}(t=$ immersion time) up to $1920 \mathrm{~s}$ immersion at $738 \mathrm{~K}$, and decreased with time for a immersion time between 1920 and $7200 \mathrm{~s}$, followed by its repeated increase and decrease. His results agreed with our results up to $6000 \mathrm{~s}$.

At $763 \mathrm{~K}$, the $\zeta$ phase once formed disappeared by prolonging immersion time. This behaviour was explained in terms of the interaction between the $\zeta$ phase and the $\delta_{1 \mathrm{P}}$ phase as follows. The time exponent for the growth of the $\delta_{1}$ phase is 0.70 and is greater than that of the $\zeta$ phase as shown in Tables 1 and 3 . In addition, the time exponent for the growth of the $\delta_{1 \mathrm{P}}$ phase which is adjacent to the $\zeta$ phase is 0.66 at $733 \mathrm{~K}$, and 0.71 at $753 \mathrm{~K}$ and is greater than that of the $\zeta$ phase. From these results and the observation of the $\zeta /$ $\delta_{1 \mathrm{P}}$ interface, the $\zeta$ phase once formed was replaced by the $\delta_{1 \mathrm{p}}$ phase. Thus the lengthwise growth of the $\zeta$ phase was offset by a $\zeta \rightarrow \delta_{1 \mathbf{P}}$ reaction. So the $\zeta$ phase grew edgewise in a row of grains and its thickness became constant and/or decreased.

The time exponent of the growth of the $\delta_{1}$ phase at $773 \mathrm{~K}$ was 0.39 which was smaller than that at the other immersion temperatures. As the $\left(\delta_{1}+\eta\right)$ phase floated into the $\eta$ phase for a immersion time longer than $1800 \mathrm{~s}$, the growth of the $\delta_{1}$ phase should be divided into two parts. The $\delta_{1}$ phase grew in propotion to $t^{0.50}$ up to $1800 \mathrm{~s}$ and then became nearly constant (about $40 \mu \mathrm{m}$ ). The result that the $\delta_{1}$ phase had a constant thickness in agreement with Hershman's results ${ }^{(2)}$. This may be explained by the zinc penetration and the drop off of the $\left(\delta_{1}+\eta\right)$ phase.

According to the phase rule, it is evident that the $\left(\delta_{1}+\eta\right)$ phase mentioned above is not a duplex phase ${ }^{(16)}$. Furthermore, because of the absence of a pronounced $\left(\delta_{1}+\eta\right) / \delta_{1}$ interface, it can be seen that the $\left(\delta_{1}+\eta\right)$ is the phase which is formed by the zinc penetration into the $\delta_{1}$ phase. From Ghoniem's results, the $\left(\delta_{1}+\eta\right)$ phase below $803 \mathrm{~K}$ is the $\left(\delta_{1 \mathrm{P}}+\eta\right)$ phase, and the $\left(\delta_{1}+\eta\right)$ phase at 813 and $833 \mathrm{~K}$ is the $\left(\delta_{1 \mathrm{~K}}+\eta\right)$ phase.

The time exponent for the growth of the $\left(\delta_{1}+\eta\right)$ phase was 0.82 at $773 \mathrm{~K}, 0.77$ at $783 \mathrm{~K}$, being greater than those of other phases. The reason for this cannot be elucidated at present. But the possible reason is as follows. Even if 
the $\delta_{1}$ phase grow according to the parabolic law, the $\delta_{1} / \eta$ interface is increased by the zinc penetration, and its thickness is increased in appearance by the solidification of the penetrated zinc. Although it is still unclear in what manner the zinc penetrates into the $\delta_{1}$ phase, a solidification stress would play a role in it $^{(1)(14)(17)}$.

Above $833 \mathrm{~K}$, the $\eta$ phase was hardly detectable in the $\delta_{1 \mathrm{~K}}$ phase, and it was estimated from the angular form of $\delta_{1 \mathrm{~K}} / \eta$ interface that the $\delta_{1 \mathrm{~K}}$ phase grew but was penetrated by zinc and simultaneously surrounded by the $\eta$ phase.

Horstmann $^{(1)}$ reported that the $\Gamma$ phase was not formed in the linear range, and that the activation energy evaluated from the temperature dependence of the iron weight loss in the parabolic range was equal to that for $\Gamma$ phase growth. He suggested that, on the basis of the activation energy, the reason for the linear attack was due to the absence of the $\Gamma$ phase.

In this work, on the other hand, the $\Gamma$ phase was formed under all the immersion conditions, in contrast with Horstmann's view of the linear attack. This problem shall be discussed in the next chapter taking the quantity of iron reacted with zinc into consideration.

\section{Quantity of iron reacted with zinc}

It can be seen from the results of Figs. 3, 4 and 5 that the sum of the quantity of iron remaining in the alloy layers and the quantity of iron dissolved into the zinc bath agrees well with the iron weight loss. So the variation in iron weight loss with temperature and time were explained by considering the variation of the other two quantities of iron reacted with zinc.

The quantity of iron remained in the alloy layers shown in Fig. 4 has three distinctive features; (1) It had a peak in the region of $793 \mathrm{~K}$. (2) Its peak value increased with immersion time up to $1200 \mathrm{~s}$ and then showed a constant value. (3) Above the peak temperature, it converged to a certain value. Comparing Figs. 2 and 4, these features corresponded to those of the total thickness of the alloy layers.
Metallographic observations show that the $\left(\delta_{1}+\eta\right)$ phase was formed and floated into the $\eta$ phase as the immersion time was longer than $1800 \mathrm{~s}$ in the region of $793 \mathrm{~K}$, and that the $\delta_{1 \mathrm{~K}}$ phase once formed dropped off into the $\eta$ phase above $833 \mathrm{~K}$. From these considerations, it seerms reasonable to ascribe the feature (1) mainly to the $\left(\delta_{1}+\eta\right)$ phase formation, the feature (2) to the drop off of the $\left(\delta_{1}+\eta\right)$ phase, and the feature (3) to the drop off of the $\delta_{1 \mathrm{~K}}$ phase.

The quantity of iron dissolved into the zinc bath shown in Fig. 5 has two distinct features; (1) It had a peak at $773 \mathrm{~K}$ for a long immersion. (2) The slope of the curves became steeper as the immersion temperature and time increased. As with the considerations of the quantity of iron remaining in the alloy layers, the feature (1) may be due to the drop off of the $\left(\delta_{1}+\eta\right)$ phase and the feature (2) due to the shift of iron from the alloy layers to molten zinc caused by the drop off of the $\delta_{1 \mathrm{~K}}$ phase. If the drop off of the $\left(\delta_{1}+\eta\right)$ phase is the only reason for the feature (1), the peak temperature would be $793 \mathrm{~K}$. In addition, after dropping off, the total thickness of the alloy layers at $793 \mathrm{~K}$ is $60-70 \mu \mathrm{m}$ thicker than that at $773 \mathrm{~K}$ and also the thickness of the $\delta_{1}$ phase differs from each other. This means that the drop off is not the only reason for the feature (1).

The iron weight loss shown in Fig. 3 has three distinct features; (1) It had a peak at $793 \mathrm{~K}$ for a short immersion, (2) and a peak at $773 \mathrm{~K}$ for a long immersion. (3) The slope of the curves became steeper as immersion temperature and time increased. The features (1) and (3) corresponded to those of the quantity of iron dissolved into the zinc bath and the feature (2) corresponded to that of the quantity of iron remaining in the alloy layers. There are few investigations which reported the features (1) and (3), except for Hershman's investigation that for a $1200 \mathrm{~s}$ immersion the iron weight loss had a peak at $793 \mathrm{~K}$ and Grubitsch's that the iron weight loss steeply increased as the immersion temperature and time increased.

There are many investigations which reported the feature (2). Among these investigations, 
Scheil ${ }^{(18)}$ reported that the quantity of iron remaining in the alloy layers had a peak at $773 \mathrm{~K}$ and was greater than the quantity of iron dissolved into the zinc bath. His results disagree with our results. His experimental procedure is that test pieces were placed at the bottom of the crucible and molten zinc was poured on it. According to his experimental procedure, the $\left(\delta_{1}+\eta\right)$ phase could not drop off into the $\eta$ phase, resulting in a thicker $\left(\delta_{1}+\eta\right)$ phase and the greater quantity of iron remained in the alloy layers.

According to the results obtained by Scheil, Hershman and this investigation, the reason for the linear attack is the formation and the drop off of the $\left(\delta_{1}+\eta\right)$ phase, in contrast with Horstmann's theory mentioned above.

The time exponent for the iron weight loss increased with immersion temperature and reached a maximum value of 0.92 at $793 \mathrm{~K}$. Then the value became minimum, 0.70 , at $803 \mathrm{~K}$ and increased again. The iron weight loss at high temperature immersions agreed with the result of Grubitsch's investigation which was carried out under an experimental condition to drop off the $\left(\delta_{1}+\eta\right)$ phase into the $\eta$ phase, and the activation energy $148 \mathrm{~kJ} /$ mol evaluated from the temperature dependence of the quantity of iron dissolved into the zinc bath above $813 \mathrm{~K}$ agreed with that obtained by Minowa ${ }^{(19)}$. On the other hand, other investigators reported the parabolic relation in this temperature range. Considering the difference of the rate constant due to the iron concentration in the bath as mentioned in Introduction, pure iron samples were immersed for $1200 \mathrm{~s}$ into a iron-saturated zinc bath in this temperature range. The iron weight loss of the iron-saturated zinc bath was smaller than that of the pure zinc bath as shown in Fig. 3.

Metallographic observations above $833 \mathrm{~K}$ show that the alloy layers consisted of the $\Gamma$ layer and the $\delta_{1 \mathrm{~K}}$ layer, and that the $\delta_{1 \mathrm{~K}}$ phase dropped off into the $\eta$ phase. So the diffusion path through the alloy layers was shortened, and the time exponent was greater than 0.50 .

\section{Conclusion}

Pure iron samples were immersed into the pure zinc baths in the temperature range of $713-873 \mathrm{~K}$, and the following conclusions were drawn.

Below $763 \mathrm{~K}$, the alloy layers were corresponding to those of a galvanized steel, but at $763 \mathrm{~K}$ the $\zeta$ phase was replaced by the $\delta_{1 \mathrm{P}}$ phase and disappeared. Between 773 and $813 \mathrm{~K}$, the $\left(\delta_{1}+\eta\right)$ phase was formed, and the phase dropped off into the $\eta$ phase for a long immersion. The total thickness of the alloy layers increased as the $\left(\delta_{1}+\eta\right)$ phase was formed, and it had a peak at $793 \mathrm{~K}$. Above $833 \mathrm{~K}$, the $\delta_{1 \mathrm{~K}}$ phase was formed on the $\Gamma$ phase and dropped off into the $\eta$ phase. For this reason, the thickness of the alloy layers was kept at a constant value, and corresponding to this the quantity of iron remaining in the alloy layers kept a constant value. The iron weight loss, corresponding to the other two quantities of iron reacted with zinc, had a peak at $793 \mathrm{~K}$ for a short immersion and had a peak at $773 \mathrm{~K}$ for a long immersion. The former was caused by the formation of the $\left(\delta_{1}+\eta\right)$ phase, the latter was caused by the drop off of the $\left(\delta_{1}+\eta\right)$ phase into the $\eta$ phase. Above $833 \mathrm{~K}$, the iron weight loss increased because of the drop off of the $\delta_{1 \mathrm{~K}}$ phase, and its time exponent was not 0.50 . There is a great difference in iron weight loss between the samples immersed into the pure zinc bath and the iron-saturated zinc bath.

\section{REFERENCES}

(1) D. Horstmann and F. Peters: Proc. of 9th Inter. Conf. on H.D.G., (1971), p. 75.

(2) A. A. Hershman: Proc. of 7th Inter. Conf. on H.D.G., (1967), p. 189.

(3) A. A. Hershman: Proc. of 8th Inter. Conf. on H.D.G., (1969), p. 3.

(4) D. Horstmann and F. Peters: Arch. Eisenhuttenw., 40 (1969), 621.

(5) H. Grubitsch: Stahl u. Eisen, 67 (1937), 819.

(6) D. H. Rowland: Trans. ASM, 40 (1948), 983.

(7) D. J. Blickwede: J. of Metals, 5 (1953), 807.

(8) F. Sjoukes: Met. Finish. J., Oct., (1971), 238.

(9) D. Horstmann: Proc. of 4th Inter. Conf. on H.D.G., (1956), 29.

(10) M. Onishi, Y. Wakamatu, K. Fukumoto and M. Sagara: J. Japan Inst. Metals, 36 (1972), 150.

(11) J. Schramm: Z. Metallk., 29 (1937), 222.

(12) M. Ghoniem and K. Löhberg: Metall, 26 (1972), 1026.

(13) G. F. Bastin, F. J. J. von Loo and G. D. Rieck: 
Z. Metallk., 65 (1974), 656.

(14) N. R. Short and J. Mackowiak: Met. Sci., 9 (1975), 496.

(15) C. Allen and J. Mackowiak: Corr. Sci., 3 (1963), 87.

(16) T. Hisamatu: Hyomenshori, Japan Inst. Metalls, (1973), p. 18.
(17) G. D. S. Price and J. A. Charles: J.I.S.I., Dec., (1973), 18.

(18) E. Scheil and H. Wurst: Z. Metallk., 29 (1937), 224.

(19) S. Minowa and M. Kosaka: J. Iron and Steel Inst. Japan, 50 (1964), 1242. 